
\title{
25 Research Sourere \\ The Effect of Uncertainty-Tolerance-based \\ Intervention in Couples on the Mental Adaptation to Disease in Women With Breast Cancer: a Randomized Clinical Trial
}

\section{Somayyeh noori}

Urmia University of Medical Sciences School of Nursing and Midwifery

Fatemeh moghaddam tabrizi ( $\square$ moghaddam.f@umsu.ac.ir)

Urmia University of Medical Sciences School of Nursing and Midwifery

Rahim Sharafkhani

Khoy University of Mrdical science

\section{Research Article}

Keywords: Breast cancer, uncertainty tolerance, couple-coping intervention, mental adjustment to cancer, experimental clinical trial

Posted Date: November 29th, 2021

DOl: https://doi.org/10.21203/rs.3.rs-985837/v1

License: (c) (1) This work is licensed under a Creative Commons Attribution 4.0 International License.

Read Full License 


\section{Abstract}

Purpose: The aim of this study was to evaluate the effect of a couple-coping intervention aiming to improve uncertainty tolerance in women diagnosed with breast cancer and their spouses on the patients' mental adaption to their disease.

Methods: The present study was conducted on 90 women with breast cancer referred to educational, medical and research centers in Urmia, IRAN, which 45 patients were randomly assigned to each treatment and control groups. Outcome measures were assessed at baseline and 6 weeks using short form mental adjustment to cancer (Mini-MAC) questionnaire. The intervention was performed in 6 groupbased sessions consisting of patients and their spouses.

Results: comparing the change from before to after intervention revealed that the effect of the intervention was significant in reducing hopeless-helpless (-5.42 \pm 2.42 in intervention group VS $-0.13 \pm$ 0.46 in control group, $\mathrm{P}<0.001)$ and anxious preoccupation $(-6.80 \pm 2.87 \mathrm{VS}-0.16 \pm 0.82, \mathrm{P}<0.001)$. It has also been significant in increasing fatalism ( $4.89 \pm 2.09$ VS $0.22 \pm 1.24)$ and fighting spirit (3.58 \pm 2.05 VS $0.11 \pm 1.61)$. The effect of intervention on changing avoidance scale was not significant $(P=0.83)$.

Conclusion: Couple-centered intervention program based on increasing uncertainty tolerance can be used to improve the situation in order to increase the patients' adjustment and it has an effective support for breast cancer patients in helping to cope with cancer.

Trial registration number: IRCT20150125020778N21.

Date of registration: 2020-12-13.

\section{Introduction}

Breast cancer is one of the most important health problems worldwide which is the most common cancer in women, accounting for $22 \%$ of cancer deaths in 2017 (1). The incidence of breast cancer in the United States has increased significantly over the past 50 years (2). It has been estimated that the number of new cases of breast cancer would increase from 1 million to 15 million annually by 2020 (3). Similar to other developing countries, the incidence of breast cancer in Iran is high, making it is the most common cancer among Iranian women which accounts for $76 \%$ of the common cancers in Iranian women $(4,5)$. Moreover, studies reported that the incidence and prevalence of breast cancer have been dramatically increased in the past decades $(6-8)$ and it is estimated that the incidence rate of breast cancer will be doubled by $2030(5,9,10)$.

Breast cancer leads to significant challenges in women and their families. Physical changes throughout the course of the disease, especially due to the side effects caused by treatment can affect the patients' self-awareness, self-confidence and sense of worth and acceptance. Following changes in patients' physical and mental condition, their social relationships and intimate interactions with others will be 
changed and the patients may feel disrupted in their family and social life $(11,12)$. Cancer can have a significant impact on couples' emotional life (13).

Patients with breast cancer cope with their condition with various strategies (14); however, coping with cancer may face numerous obstacles. Intolerance of uncertainty in individuals with cancer is shown to affect patients' mental wellbeing and their coping strategies (15). Additionally, uncertainty can adversely affect the quality of life in patients with cancer and their spouses $(16,17)$. To the best of our knowledge, few studies have aimed to evaluate the effect of intervention targeting uncertainty on patients' coping status. Moreover, only one study was found to target couples in this matter, concerning the important role of spouses in supporting the patients to mentally adapt to the disease $(14,18)$. The aim of this study was to evaluate the effect of a couple-coping intervention aiming to improve uncertainty tolerance in women diagnosed with breast cancer and their spouses on the patients' mental adaption to their disease.

\section{Material And Methods Participants}

The present study is an experimental clinical trial that was conducted on women with breast cancer referred to educational, medical and research centers in Urmia, west Azerbaijan, Iran in 2020-2021 (clinical trial code: IRCT20150125020778N21). The study population included women with breast cancer The inclusion criteria of patients were as follows: patients aged 30 to 60 years, having breast cancer stage 1, 2 and 3 based on the pathology results, having information about breast cancer, more than 48 hours after chemotherapy, was married and has lived with his wife for more than 12 months, not attending another training session, having mental health (the patient and his wife) on the basis that they do not have a history of hospitalization in psychiatric wards and a history of taking anti-drugs. The occurrence of any stressful event for the patient or first class members of the patient's family during the study, the absence of more than two sessions related to the intervention, other cancers or any lifethreatening illness caused the patient to exude from the study. Taking into inclusion criteria of present study, it was decided that 200 couples to enter the study by convenience sampling method and using an envelope containing even or odd numbers, 100 patients were randomly assigned to each group but due to the prevalence of Covid-19 from March 2020, which itself became a stressful event and could be affect the results of the study, the ethics committee decided to stop sampling and eventually 90 patients were considered as final cases which 45 patients were randomly assigned to each treatment and control groups (Figure 1).

\section{Measurement tools}

A brief questionnaire was completed to obtain basic characteristics and disease related information including age, number of child, patient and her spouse education level, economic status, stage of breast cancer, duration of awareness about cancer diagnosis, and surgery status. Mental adjustment was measured using a shortened form of the Mental Adjustment to Cancer (Mini-MAC) questionnaire that its factor structure and psychometric properties evaluated in a sample of Iranian adults who suffer from 
cancer (19). This questionnaire has 5 subscales and the higher the score on each subscale, the stronger the use of that coping strategy and this means that the subject uses that subscale as a style or strategy for adapting to more cancer. Items are scored on a 4-point Likert scale from 1 = "Definitely does not apply" to 4 = "Definitely applies to me". HH: Helpless-Hopeless, AP: Anxious Preoccupation, CA: Cognitive Avoidance, FA: Fatalism, and FS: Fighting Spirit are the Mini-Mac subscales. In the present study, Based on pre-treatment information of 25 primary patients the reliability of the Mini-MAC questionnaire was assessed through internal consistency, with a Cronbach's alpha coefficient of 0.79 for the HH subscale, 0.87 for AP, 0.71 for CA, 0.83 for FA, and 0.72 for the CA subscale were achieved.

\section{Intervention}

Design interventions included helping to develop the ability to tolerate ambiguous situations, reinforcing positive beliefs about worry, cognitive avoidance, and negative orientation toward the problem. The intervention was performed in 6 group-based sessions consisting of patients and their spouses in groups of 6 to 10 people. The duration of each session was about 1.5-2 hours per week for 6 weeks. The topics and strategies used in the meetings are detailed in Table 1. To evaluate the participants in both groups, a notebook was provided to record their daily behavior. The control group did not receive any intervention program before the post-test and only received routine care in cancer patients that all cancer patients receive. At the end of the sixth session, the questionnaires were completed again and the results were entered, cleaned and analyzed by software. 
Table 1

The topics and strategies used in the groups-based meetings in the intervention group.

\section{Session Context}

First Introducing the researcher to the patient and the patient's spouse, talking about the patient's current condition, explaining the intervention steps

Second Help build the ability to tolerate ambiguous situations through strategies to increase the tolerance of uncertainty in life, strategies for dealing with the surprises of life, strategies for planning for the future rather than predicting the future, relaxation strategies, communication skills and humor, problem-solving skills, making sense of each day and addressing questions and answers along with homework

Third Strengthen positive beliefs about worry by creating positive beliefs, creating a sense of calm and hope for the future, having a positive attitude towards life, appreciating blessings and being thankful, ways to reduce anxiety and depression, release from isolation and increasing positive emotions, emphasizing on the daily use of optimism strategies and addressing the desired questions and answers along with homework and review of homework in the previous session

Fourth Cognitive avoidance by doing affairs that make life enjoyable. Belief in a purposeful life such as setting a to-do list, setting the right of priority of each task over another, challenging negative thoughts, replacing and conflicting with negative thoughts, and addressing the desired questions and answers along with homework and review of homework in the previous session

Fifth Avoid negative orientation by accepting the problem, forgiving yourself, advising to breathe deeply when negative brainstorming, writing about tensions and life events, relaxation techniques, focusing on things and affairs that can be controlled, practicing focus senses, and addressing the desired questions and answers along with homework and review of homework in the previous session

Sixth $\quad$ Review and summarize, run post-test

\section{Statistical analysis}

Descriptive statistics of patient's characteristics were reported as mean \pm SD for normal distributed continuous variables, median (quartile 1 - quartile 3) for non-normal continuous variables and frequency (percent) for categorical variables. Study variables compared between intervention and control groups using independent samples T-test, Mann-Whitney $\mathrm{U}$ test or chi-square test with exact $\mathrm{p}$-value as appropriate. Within comparisons (before/after) were performed using Wilcoxon signed rank test. Normality assumption examined by Shapiro-Wilk test. The P-value $<0.05$ considered as significant level and all statistical analysis were done by IBM SPSS Statistics 25 .

\section{Results}

Baseline characteristics and disease related features of 90 patients, randomly assigned to the intervention and control groups, are shown in Table 2. The mean (median) and distribution (frequency, percent) of measured variables were compared between groups. Study participants did not significantly 
differed considering age, number of child, economic status, education level and their husband's education level, economic status, and home ownership $(P>0.05)$. In terms of disease related factors including disease onset, disease stage and surgery status, patients were homogeneous in the two groups and there was no significant difference $(P>0.05)$. 
Table 2

Baseline characteristics of participants across study groups.

\begin{tabular}{|c|c|c|c|c|}
\hline Variables & $\begin{array}{l}\text { Total } \\
\mathrm{n}=90\end{array}$ & $\begin{array}{l}\text { Intervention } \\
\mathrm{n}=45\end{array}$ & $\begin{array}{l}\text { Control } \\
n=45\end{array}$ & P-value \\
\hline Age & $46.31 \pm 8.14$ & $47.44 \pm 8.94$ & $45.18 \pm 7.17$ & 0.19 \\
\hline No of child & & & & 0.46 \\
\hline 0 & $5(5.6)$ & $1(2.2)$ & $4(8.9)$ & \\
\hline 1 & $15(16.7)$ & $7(15.6)$ & $8(17.8)$ & \\
\hline$\geq 2$ & $70(77.8)$ & $37(82.2)$ & $33(73.3)$ & \\
\hline Economic status & & & & 0.64 \\
\hline low & $28(31.1)$ & $12(26.7)$ & $16(35.6)$ & \\
\hline medium & $55(61.1)$ & $30(66.7)$ & $25(55.6)$ & \\
\hline high & $7(7.8)$ & $3(6.7)$ & $4(8.9)$ & \\
\hline Home ownership & & & & 1.00 \\
\hline rent & $22(24.4)$ & $11(24.4)$ & $11(24.4)$ & \\
\hline personal & $68(75.6)$ & $34(75.6)$ & $34(75.6)$ & \\
\hline Education & & & & 0.41 \\
\hline under diploma & $45(50.0)$ & $20(44.4)$ & $25(55.6)$ & \\
\hline diploma & $33(36.7)$ & $17(37.8)$ & $16(35.6)$ & \\
\hline university & $12(13.3)$ & $8(17.8)$ & $4(8.9)$ & \\
\hline Spouse education & & & & 0.11 \\
\hline under diploma & $43(47.8)$ & $17(37.8)$ & $26(57.8)$ & \\
\hline diploma & $24(26.7)$ & $16(35.6)$ & $8(17.8)$ & \\
\hline university & $23(25.6)$ & $12(26.7)$ & $11(24.4)$ & \\
\hline Disease onset* & $11.0(5.8-21.0)$ & $12.0(7.0-23.5)$ & $10.0(4.5-18.0)$ & 0.23 \\
\hline Disease stage & & & & 0.62 \\
\hline
\end{tabular}

Data represented as frequency (percent), mean \pm SD or median (Q1 - Q3).

The percentage for categorical variables is calculated in columns and the total column percentage is equal to 100.

* How long has the participant been informed of the disease? (Month). 


\begin{tabular}{|lllll|}
\hline Variables & $\begin{array}{l}\text { Total } \\
\mathbf{n = 9 0}\end{array}$ & $\begin{array}{l}\text { Intervention } \\
\mathbf{n = 4 5}\end{array}$ & $\begin{array}{l}\text { Control } \\
\mathbf{n = 4 5}\end{array}$ & P-value \\
\hline I & $19(21.1)$ & $11(24.4)$ & $8(17.8)$ & \\
\hline II & $45(50.0)$ & $23(51.1)$ & $22(48.9)$ & 0.28 \\
\hline III & $26(28.9)$ & $11(24.4)$ & $15(33.3)$ & \\
\hline Surgery status & $52(57.8)$ & $29(64.4)$ & $22(51.1)$ \\
\hline yes & $38(42.2)$ & $16(35.6)$ & \\
\hline no & & \\
\hline Data represented as frequency (percent), mean \pm SD or median (Q1 - Q3). & \\
\hline $\begin{array}{l}\text { The percentage for categorical variables is calculated in columns and the total column percentage is } \\
\text { equal to 100. }\end{array}$ & \\
\hline
\end{tabular}

The mean of MAC dimensions compared between intervention and control groups at the before and after intervention (Table 3). Considering study time, at the before intervention, all dimensions did not significantly differed between intervention and control groups $(P>0.05)$ whereas, after intervention, except for avoidance scale $(P=0.51)$ other dimensions of Mac were significantly differed between the two groups $(\mathrm{P}<0.001)$; For hopeless-helpless and anxious preoccupation, a significant decrease was observed in the intervention group compared to the control group and fatalism along with fighting spirit increased significantly in the intervention group. 
Table 3

Intervention effect evaluation: Comparing MAC dimensions between study groups at the before and after intervention.

\begin{tabular}{|c|c|c|c|c|}
\hline Variables & & Before & After & P-value ${ }^{\#}$ \\
\hline \multirow[t]{3}{*}{ Hopeless-Helpless } & Intervention & $21.24 \pm 2.19$ & $15.82 \pm 2.06$ & $<0.001$ \\
\hline & Control & $20.64 \pm 2.78$ & $20.51 \pm 2.91$ & 0.06 \\
\hline & P-value* & 0.44 & $<0.001$ & \\
\hline \multirow[t]{3}{*}{ Anxious Preoccupation } & Intervention & $26.71 \pm 2.12$ & $19.91 \pm 2.14$ & $<0.001$ \\
\hline & Control & $26.53 \pm 3.00$ & $26.38 \pm 3.24$ & 0.24 \\
\hline & P-value* & 0.44 & $<0.001$ & \\
\hline \multirow[t]{3}{*}{ Cognitive Avoidance } & Intervention & $11.60 \pm 1.39$ & $11.40 \pm 1.21$ & 0.59 \\
\hline & Control & $11.44 \pm 1.22$ & $11.31 \pm 1.49$ & 0.24 \\
\hline & P-value* & 0.42 & 0.51 & \\
\hline \multirow[t]{3}{*}{ Fatalism } & Intervention & $12.64 \pm 1.54$ & $17.53 \pm 1.53$ & $<0.001$ \\
\hline & Control & $13.29 \pm 1.73$ & $13.51 \pm 2.07$ & 0.33 \\
\hline & P-value* & 0.08 & $<0.001$ & \\
\hline \multirow[t]{3}{*}{ Fighting Spirit } & Intervention & $8.00 \pm 1.67$ & $11.58 \pm 1.10$ & $<0.001$ \\
\hline & Control & $8.60 \pm 1.70$ & $8.71 \pm 2.03$ & 0.22 \\
\hline & P-value* & 0.06 & $<0.001$ & \\
\hline * Mann-Whitney U test. & & & & \\
\hline
\end{tabular}

Also, the mean of MAC dimensions compared along study times (before and after) in the intervention and control groups separately (Table 2). In the control group, all dimensions did not significantly differ between before and after intervention $(P>0.05)$ whereas, in the intervention group a significant decrease was observed for hopeless- helpless and anxious preoccupation while fatalism and fighting spirit were significantly increased after intervention. The avoidance scale did not significant differences between before and after intervention $(P=0.59)$.

Finally, the change from before to after intervention, which is known as the intervention effect, was calculated for MAC dimensions in "difference" column (Table 4) and mean of this value was compared between intervention and control group. Comparisons shows that the effect of the intervention was significant in reducing hopeless-helpless (-5.42 \pm 2.42 in intervention group VS $-0.13 \pm 0.46$ in control 
group, $\mathrm{P}<0.001)$ and anxious preoccupation $(-6.80 \pm 2.87 \mathrm{VS}-0.16 \pm 0.82, \mathrm{P}<0.001)$. It has also been significant in increasing fatalism (4.89 \pm 2.09 VS $0.22 \pm 1.24)$ and fighting spirit ( $3.58 \pm 2.05$ VS $0.11 \pm$ 1.61). The effect of intervention on changing avoidance scale was not significant $(P=0.83)$.

Table 4

Intervention effect evaluation: Comparison of score changes between two groups (Mean change \pm SD: after score-before score)

\begin{tabular}{|llll|}
\hline Variables & Intervention & Control & P-value $^{*}$ \\
\hline Hopeless-Helpless & $-5.42 \pm 2.42$ & $-0.13 \pm 0.46$ & $<0.001$ \\
\hline Anxious Preoccupation & $-6.80 \pm 2.87$ & $-0.16 \pm 0.82$ & $<0.001$ \\
\hline Cognitive Avoidance & $-0.20 \pm 1.58$ & $-0.13 \pm 0.87$ & 0.83 \\
\hline Fatalism & $4.89 \pm 2.09$ & $0.22 \pm 1.24$ & $<0.001$ \\
\hline Fighting Spirit & $3.58 \pm 2.05$ & $0.11 \pm 1.61$ & $<0.001$ \\
\hline * Mann-Whitney U test. & & & \\
\hline
\end{tabular}

The percentage of score change in MAC dimensions revealed that the maximum change (increasing) observed for fighting spirit (53\% for intervention versus $6.7 \%$ for control group) and fatalism ( $40.5 \%$ for intervention versus $1.7 \%$ for control group) is in the next rank. The percentage reduction of the score of Hopeless-Helpless and Fighting Spirit subscales shows that the percentage of reduction was higher in the intervention group compared to the control group (Figure 2).

\section{Discussion}

As being diagnosed with breast cancer causes a great distress in patients struggling to be cured, psychosocial factors should be considered as an important part of breast cancer treatment (20). For patients with breast cancer, intolerance of uncertainty is a huge problem. Intolerance of uncertainty is associated with high levels of worry and its maintenance in breast cancer patients (21). Additionally, it is suggested that intolerance of uncertainty is associated with worsened depressive symptoms and concerns about cancer after being treated (22). It is suggested that early detection of emotional needs in the process of breast cancer treatment not only reduces the cost of cancer treatment, but also improves the quality of life of the patients (23). Thus, this study aimed to evaluate the effect of an intervention aiming to improve uncertainty tolerance in women diagnosed with breast cancer and their spouses on patients' mental adaptation to their disease. The results of the current study indicated that the intervention was effective to improve hopelessness and helplessness, anxious preoccupation, fatalism and fighting spirit in patients with breast cancer.

The results of the current study have shown that the hopelessness-helplessness was significantly decreased in intervention group patients in comparison with control group. Hope plays a crucial role in 
breast cancer treatment, since the diagnosis of the disease could be assumed as a threat or a death sentence (24). A study which conducted to assess the interventions which aim to increase hope in patients with breast cancer has a critical role to increase their quality of life and help them to cope with their disease (25). Kazemi et al conducted a study in 2010 to evaluate the effect of logotherapy training on reducing hopelessness in women with breast cancer and reported that people who have higher hopes during their treatment are more resistant to long-term painful treatments, side effects of chemotherapy and radiation therapy (26). In a study aimed to investigate the association between psychosocial adaptation and hopelessness in women with breast cancer, it was reported that psychosocial adaptation is poor in $63.3 \%$ of women with breast cancer. it has also demonstrated that as hopelessness increase, psychosocial adaptation in patients with breast cancer decrease (27). It could be estimated that interventions which aim to increase the patients hope might also help them to psychosocially adapt themselves to their new conditions.

The current study showed that increasing uncertainty tolerance decreases anxious preoccupation in patients with breast cancer. Anxiety and depressive disorders are psychiatric disorders which are common in breast cancer patients. Anxiety disorder could be found in 1 to $49 \%$ of breast cancer patients (28). In addition, depressive disorder is found in 1.5 to $46 \%$ of these patients $(28,29)$, varied in time and population. Morris et al suggested that the prevalence of depression in women went under mastectomy for breast cancer was 22\% (30). Moreover, Meyer and Aspergren reported that $30 \%$ of women with fiveyear treatment of breast cancer had anxiety or depressive symptoms (31). Decreasing anxiety level in patients may help them to cope with their disease easier. Anxiety and depression are common mental disorders in most patients with cancer, leading to lack of energy, inappetence in continuing treatment and reducing the quality of life of them $(32,33)$.

The current study was effective in increasing fighting spirit in patients with breast cancer. Adopting a fighting spirit improves the chances of survival in cancer patients (34). In this regard, the results of the study of Mohammad et al. (2018) showed that psychotherapy intervention in breast cancer patients helps them to better adapt to the disease and have a better fighting spirit (23). The results of Dastan et al.'s study also showed that psychotherapy intervention sessions increase the fighting spirit in patients with breast cancer. Based on the results of their study, psychological interventions and training cause help cancer patients to cope with their disease (35). The current study was also effective to decrease fatalism in patients with breast cancer. The results of Dastan et al.'s study reported that there was a significant decrease in the mean scores of fatalism, which indicates the effectiveness of the intervention for mental adjustment to breast cancer (35).

\section{Conclusion}

This study showed that a couple-centered intervention program based on increasing uncertainty tolerance can be an effective support for breast cancer patients in helping to cope with cancer. Educating patients' spouses and gaining their support can help them be relieved of stress in various areas such as emotional, psychological and psychological. Also, by reminding the spouses of the difficulties of adjustment in these 
patients, such as depression, feelings of hopelessness, fatigue, and anxiety, their help can be used to improve the situation in order to increase the patients' adjustment.

\section{Declarations}

\section{Acknowledgment:}

We would like to thank the patients, their families, and caregivers who participated and cooperated in this study.

\section{Funding:}

This work was supported by Urmia University of medical sciences. The funder provided financial support and study samples but did not involve in experimental design, data collection, and data analysis.

\section{Conflict of interest:}

Authors have no conflict of interest to declare. The authors have full control of all primary data and agreed to allow the journal to review their data if requested.

\section{Availability of data and material:}

The data that support the findings of this study are available from the corresponding author, [FMT], upon reasonable request.

\section{Code availability:}

“Not applicable”

\section{Authors' contribution:}

fatemeh moghaddam tabrizi, somayyeh noori contributed to the study conception and designed and conducted the research. Data were collected by somayyeh nori. Rahim sharafkhani formed randomization and analyzed, performed statistical analysis. The first draft of the manuscript was written by somayyeh nori and fatemeh moghaddam and all authors commented on previous versions of the manuscript.

\section{Ethical approval:}

The ethical considerations of the research were approved by the Institutional Review Board and the Ethics Committee of Urmia University of Medical Sciences (IR.umsu.rec.1398.032).

\section{Consent to participate:}


Participants were given detailed information about the study and make sure that confidentiality will be protected. Informed and written consent was obtained prior to data collection.

\section{Consent for publication:}

"Not applicable"

\section{References}

1. Miller KD, Fidler-Benaoudia M, Keegan TH, Hipp HS, Jemal A, Siegel RL. Cancer statistics for adolescents and young adults, 2020. CA Cancer J Clin. 2020;70(6):443-59. doi:10.3322/caac.21637

2. Berek JS. Berek \& Novak's Gynecology Essentials: Lippincott Williams \& Wilkins; 2020.

3. Kalan FarmanFarma K, Zareban I, Jalili Z, Shahraki pour M, Lotfi B. The Effect of Education on Condition of Knowledge, Attitude and Preventive Behaviors of Breast Cancer in Female Teachers at Guidance Schools in Zahedan. Journal of Torbat Heydariyeh University of Medical Sciences. 2013;1(3):65-73.

4. Torre LA, Siegel RL, Ward EM, Jemal A. Global Cancer Incidence and Mortality Rates and Trends--An Update. Cancer Epidemiol Biomarkers Prev. 2016;25(1):16-27. doi:10.1158/1055-9965.Epi-15-0578

5. Mousavi SM, Gouya MM, Ramazani R, Davanlou M, Hajsadeghi N, Seddighi Z. Cancer incidence and mortality in Iran. Ann Oncol. 2009;20(3):556-63. doi:10.1093/annonc/mdn642

6. Fazel A, Hasanpour-Heidari S, Salamat $F$, et al. Marked increase in breast cancer incidence in young women: A 10-year study from Northern Iran, 2004-2013. Cancer epidemiology. 2019;62:101573.

7. Dolatkhah R, Somi MH, Jafarabadi MA, et al. Breast cancer survival and incidence: 10 years cancer registry data in the northwest, Iran. International journal of breast cancer. 2020;2020.

8. Bab S, Abdifard E, Elyasianfar S, Mohammadi P, Heidari M. Time trend analysis of breast cancer in Iran and its six topographical regions: a population-based study. Journal of medicine and life. 2019;12(2):140.

9. Taghavi A, Fazeli Z, Vahedi M, et al. Increased trend of breast cancer mortality in Iran. Asian Pac J Cancer Prev. 2012;13(1):367-70. doi:10.7314/apjcp.2012.13.1.367

10. Valipour AA, Mohammadian M, Ghafari M, Mohammadian-Hafshejani A. Predict the future incidence and mortality of breast cancer in Iran from 2012-2035. Iranian journal of public health. 2017;46(4):579-80.

11. KARIMOI HM, POURDEHGHAN M, FAGHIHZADEH S, MONTAZERI A, MILANI JM. THE EFFECTS OF GROUP COUNSELING ON SYMPTOM SCALES OF LIFE QUALITY IN PATIENTS WITH BREAST CANCER TREATED BY CHEMOTHERAPY. JOURNAL OF KERMANSHAH UNIVERSITY OF MEDICAL SCIENCES (BEHBOOD). 2006;10(1):-.

12. Koopman $C$, Angell K, Turner-Cobb JM, et al. Distress, coping, and social support among rural women recently diagnosed with primary breast cancer. Breast J. 2001;7(1):25-33. doi:10.1046/j.15244741.2001.007001025.x 
13. Hagedoorn M, Sanderman R, Bolks HN, Tuinstra J, Coyne JC. Distress in couples coping with cancer: a meta-analysis and critical review of role and gender effects. Psychol Bull. 2008;134(1):1-30. doi:10.1037/0033-2909.134.1.1

14. Al-Azri M, Al-Awisi H, Al-Moundhri M. Coping With a Diagnosis of Breast Cancer-Literature Review and Implications for Developing Countries. The Breast Journal. 2009;15(6):615-22. doi:https://doi.org/10.1111/j.1524-4741.2009.00812.x

15. Kurita K, Garon EB, Stanton AL, Meyerowitz BE. Uncertainty and psychological adjustment in patients with lung cancer. Psychooncology. 2013;22(6):1396-401. doi:10.1002/pon.3155

16. Shaha M, Cox CL, Talman K, Kelly D. Uncertainty in breast, prostate, and colorectal cancer: implications for supportive care. J Nurs Scholarsh. 2008;40(1):60-7. doi:10.1111/j.15475069.2007.00207.x

17. Wonghongkul T, Dechaprom N, Phumivichuvate L, Losawatkul S. Uncertainty appraisal coping and quality of life in breast cancer survivors. Cancer Nurs. 2006;29(3):250-7. doi:10.1097/00002820200605000-00014

18. Scott JL, Halford WK, Ward BG. United we stand? The effects of a couple-coping intervention on adjustment to early stage breast or gynecological cancer. J Consult Clin Psychol. 2004;72(6):112235. doi:10.1037/0022-006x.72.6.1122

19. Patoo M, Allahyari AA, Moradi AR, Payandeh M. Iranian Version of the Mini-Mental Adjustment to Cancer Scale: Factor Structure and Psychometric Properties. J Psychosoc Oncol. 2015;33(6):675-85. doi:10.1080/07347332.2015.1082169

20. Shapiro SL, Lopez AM, Schwartz GE, et al. Quality of life and breast cancer: relationship to psychosocial variables. Journal of clinical psychology. 2001;57(4):501-19.

21. Freeston MH, Rhéaume J, Letarte $H$, Dugas MJ, Ladouceur R. Why do people worry? Personality and individual differences. 1994;17(6):791-802.

22. Costa-Requena G, Rodríguez A, Fernández R, Palomera E, Gil FL. Cognitive processing variables in breast cancer: Worry and distress at the end of treatment. Journal of Cancer Education. 2011;26(2):375-9.

23. mohammed S, Ahmed S, Ebraheem M, Mahmoud M. Effectiveness of Psycho-educational Nursing Program on Emotional Distress and Mental Adjustment in Women with Breast Cancer. Egyptian Journal of Health Care. 2018;9(1):1-15. doi:10.21608/ejhc.2018.9991

24. Balsanelli ACS, Grossi SAA. Predictors of hope among women with breast cancer during chemotherapy. Revista da Escola de Enfermagem da USP. 2016;50:00898-904.

25. Gumus AB, Cam O, Malak AT. Relationships between psychosocial adjustment and hopelessness in women with breast cancer. Asian Pac J Cancer Prev. 2011;12(2):433-8.

26. SHOAA KAZEMI M, SAADATI M. THE STUDY OF EFFECTIVE LOGO THERAPY TRAINING ON REDUCTION HOPELESSNESS IN BREAST CANCER WOMEN'S IN TEHRAN CITY. IRANIAN QUARTERLY JOURNAL OF BREAST DISEASE. 2010;3(1-2):-. 
27. Gumus AB, Cam O, Malak AT. Relationships between psychosocial adjustment and hopelessness in women with breast cancer. Asian Pac J Cancer Prev. 2011;12(2):433-8.

28. Morasso G, Costantini M, Viterbori P, et al. Predicting mood disorders in breast cancer patients. European Journal of Cancer. 2001;37(2):216-23.

29. Massie MJ. Prevalence of depression in patients with cancer. JNCI Monographs. 2004;2004(32):5771.

30. Morris T, Steven Greer H, White P. Psychological and social adjustment to mastectomy. A two-year follow-up study. Cancer. 1977;40(5):2381-7.

31. Meyer L, Aspegren K. Long-term psychological sequelae of mastectomy and breast conserving treatment for breast cancer. Acta Oncologica. 1989;28(1):13-8.

32. Rajandram RK, Ho SM, Samman N, Chan N, McGrath C, Zwahlen RA. Interaction of hope and optimism with anxiety and depression in a specific group of cancer survivors: a preliminary study. BMC Res Notes. 2011;4:519. doi:10.1186/1756-0500-4-519

33. Ng CG, Mohamed S, See MH, et al. Anxiety, depression, perceived social support and quality of life in Malaysian breast cancer patients: a 1-year prospective study. Health Qual Life Outcomes. 2015;13:205. doi:10.1186/s12955-015-0401-7

34. Coyne JC, Tennen H. Positive psychology in cancer care: bad science, exaggerated claims, and unproven medicine. Ann Behav Med. 2010;39(1):16-26. doi:10.1007/s12160-009-9154-z

35. Dastan NB, Buzlu S. Psychoeducation intervention to improve adjustment to cancer among Turkish stage I-II breast cancer patients: a randomized controlled trial. Asian Pac J Cancer Prev. 2012;13(10):5313-8. doi:10.7314/apjcp.2012.13.10.5313

\section{Figures}




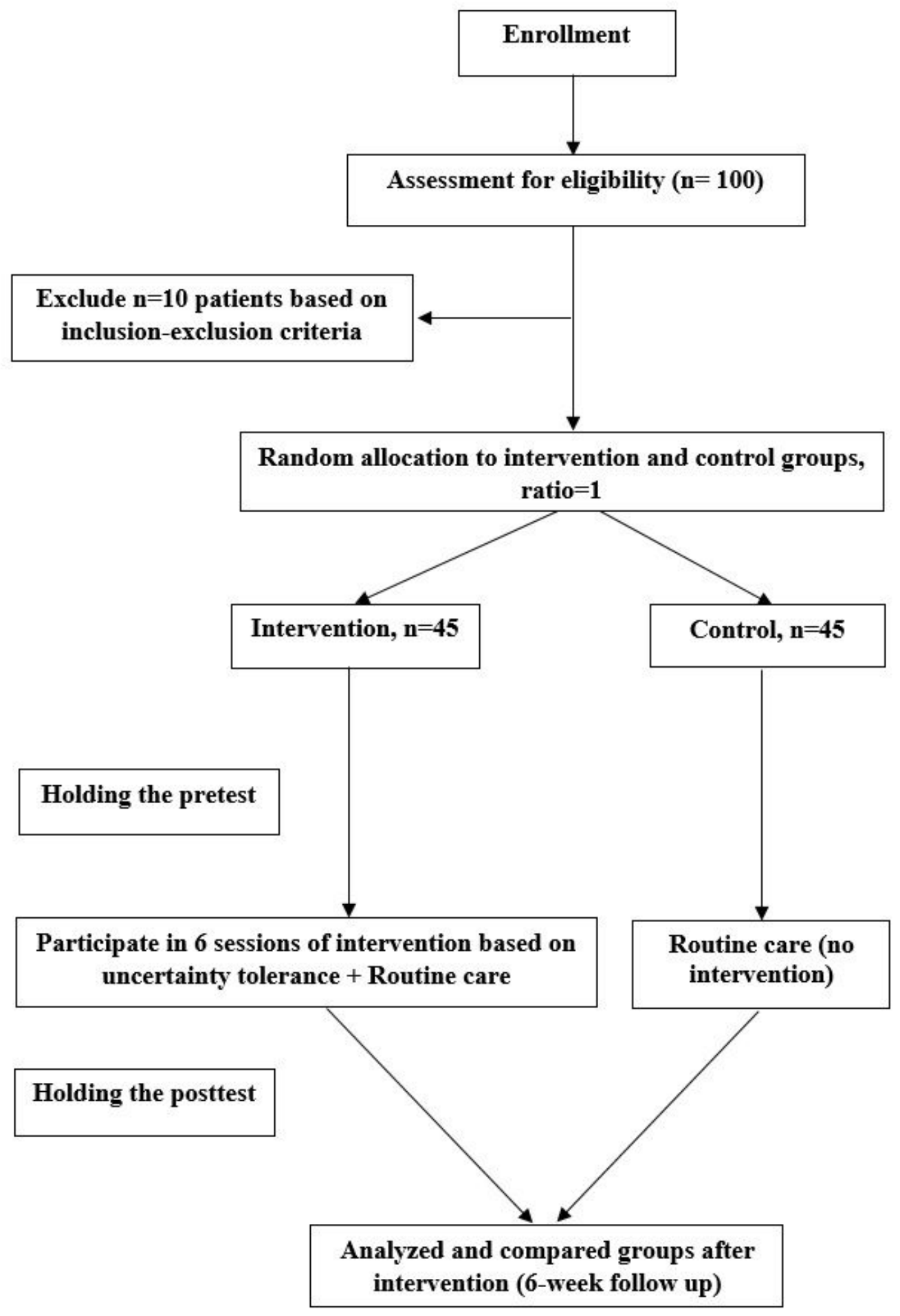

Figure 1

Participants 'flow chart: number of recruited volunteer and actual number of participants included in data analyses. 


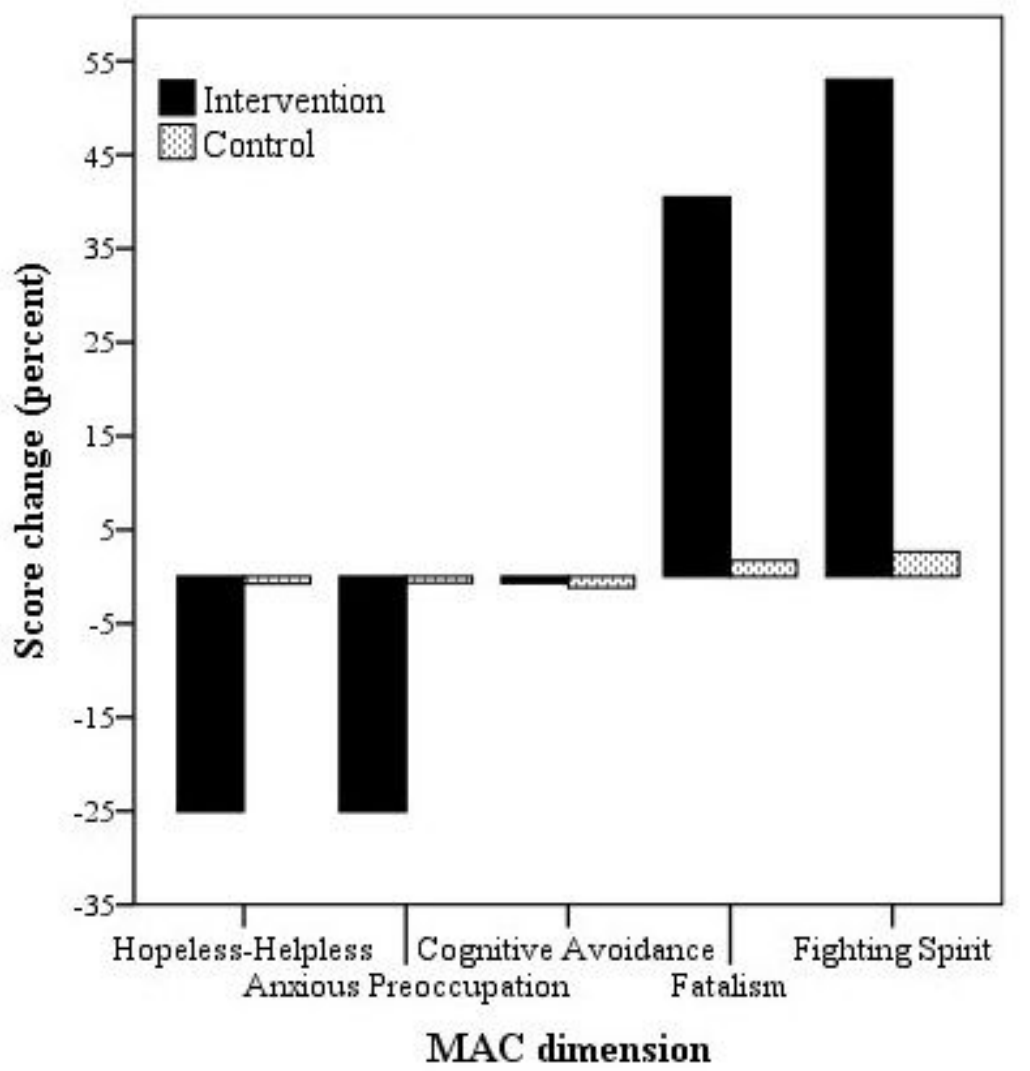

\section{Figure 2}

Bar chart of percentage changes in Mac dimension score. percentage change defined as: (after scorebefore score)/ before score)*100). 